\title{
Optimization process for thin-walled high performance concrete sandwich panels
}

\author{
Hodicky, Kamil; Hulin, Thomas; Schmidt, Jacob Wittrup; Stang, Henrik
}

Published in:

Proceedings of the Fourth International FIB Congress

Publication date:

2014

Link back to DTU Orbit

Citation (APA):

Hodicky, K., Hulin, T., Schmidt, J. W., \& Stang, H. (2014). Optimization process for thin-walled high performance concrete sandwich panels. In Proceedings of the Fourth International FIB Congress IMC - FIB.

\section{General rights}

Copyright and moral rights for the publications made accessible in the public portal are retained by the authors and/or other copyright owners and it is a condition of accessing publications that users recognise and abide by the legal requirements associated with these rights.

- Users may download and print one copy of any publication from the public portal for the purpose of private study or research.

- You may not further distribute the material or use it for any profit-making activity or commercial gain

- You may freely distribute the URL identifying the publication in the public portal

If you believe that this document breaches copyright please contact us providing details, and we will remove access to the work immediately and investigate your claim. 


\title{
OPTIMIZATION PROCESS FOR THIN-WALLED HIGH PERFORMANCE CONCRETE SANDWICH PANELS
}

\author{
Hodicky, K., Hulin, T., Schmidt, J.W. and Stang, H. \\ Department of Civil Engineering, Technical University of Denmark, Brovej 118, Kongens Lyngby, \\ Denmark.
}

\begin{abstract}
A Nearly zero energy buildings are to become a requirement as part of the European energy policy. There are many ways of designing nearly zero energy buildings, but there is a lack of knowledge on optimization processes in the sense of structurally and thermally efficient design with an optimal economical solution. The present paper aims to provide multi-objective optimisation procedure addressed to structural precast thin-walled High Performance Concrete Sandwich Panels (HPCSP). The research aim is concerned with developing a tool that considers the cost of HPCSP materials along with the specifications of the design constrains and variables. The tool integrates the processes of HPCSP design, quantity take-off and cost estimation into a single system that would provide different costs for different HPCSP designs. The proposed multi-objective optimisation scheme results into derivation of basic design recommendations, regarding the material's strength and HPCSP's geometrical parameters that fulfil the objective of minimum cost.
\end{abstract}

Keywords: Multi-objective optimization, High Performance Concrete, Sandwich panels, Minimum cost, Design constraints.

\section{Introduction}

According to European Uninon, residential and commercial buildings are responsible for about $40 \%$ of the total energy consumption and CO2 emissions in Europe. Therefore, ambitious targets for energy consumption of new buildings are being implemented, and by the year 2020 nearly zero energy buildings will become a requirement in the European Union. In consequence of this the building sector has faced a growing demand for development and manufacturing of modular, light and strong building elements having a high degree of insulation, a long life time, a low CO2 emission, a low consumption of raw material, and an attractive surface with minimum maintenance. Moreover, architects and engineers will face the challenge of designing these new buildings with only limited extra cost compared to new buildings today. Thus finding the balance between structural performances and economically optimal solution in building design is needed. The thin-walled High Performance Concrete Sandwich Panels (HPCSPs) are an interesting option for future low or plus energy building constructions.

The main objective of the research summarized in this paper is to present a general optimization procedure of HPCSPs in the sense of structurally and thermally efficient design with an optimal economical solution. A quick and accurate systematic optimization approach is based on material cost function in HPCSP design. The research aims at developing a tool that considers the cost of HPCSP materials along with the specifications of the design constrains and variables. The tool integrates the processes of HPCSP design, quantity take-off and cost estimation; thus a change of any parameter or design constrain in one process would have its effect on the other processes. The suggested optimization procedure could set the ground for further research in predicting optimal design dimensions, mixture proportions and structural designs and systems. 


\section{Background and description of thin-walled HPCSP}

The thin-walled HPCSPs are structurally, thermally and environmentally efficient elements for exterior walls in multi-stories residential, commercial and warehouse buildings. The HPCSPs have several beneficial features such as high quality, proven durability, fast erection, and attractive architectural appearance (Einea et al. 1994). A typical HPCSP consists of two precast High Performance Concrete (HPC) plates and layer of insulation separates the two HPC plates. The connectors penetrate the insulation layer and join the two HPC plates.

The HPCSPs may be designed as: non-composite, partially composite or fully composite (Rizkalla et al. 2009). The degree of composite action depends on the nature of the connection between two HPC plates. The connections between the plates have been traditionally made by using bent reinforcing bars or various specially-designed steel or non-metallic connectors (Frankl et al. 2008). Increasing degree of composite action between two HPC plates using any type of these connectors increases the structural capacity of the HPCSP making it more efficient. However, increasing degree of composite action leads to significant thermal efficiency reduction of the panel through thermal bridges (Wade et al. 1998). Recently, the sandwich panel design concept has leaped forward by introducing fiber reinforced polymer, or FRP, shear reinforcement grids allowing for benefits that make the use of these panels even more desirable than ever before as they have a relatively low thermal conductivity compared to steel (Soriano \& Rizkalla, unpubl.). Furthermore, undesirable thermal bowing may occur due to different temperatures between interior and exterior surfaces. The thermal deflections in long HPCSPs can be significant and may cause cracking due to southern exposure especially at building corners. Recent research and development work indicates that load-bearing thin-walled HPCSPs are prone to structural cracking due to the combined effect of shrinkage and high temperature load. The stiffness of the connectors is proportional to the thermal deflection and thus has significant role in the design of HPCSPs. The connector design represents tradeoff between development of fully composite action for resisting lateral loads, and reduction of composite action to limit thermal deflections. Two main categories of connectors exist: non-shear connectors and shear connectors. Non-shear connectors are used in non-composite HPCSPs to resist insignificant shear forces. These connectors primarily resist the tensile forces required to maintain integrity of the panel by keeping two HPC plates attached. Shear connectors must provide adequate stiffness and strength to create significant composite behaviour in the panel and resist the ultimate and service loads of the panel. Bond between the insulation and HPC plates provides some shear transfer, but this bond diminishes over time and will not provide full strength over the life time of the panel (Salmon et al. 1997). The insulation layer mainly provides thermal efficiency of the panel. This efficiency depends on the thickness of the insulation material, amount and type of penetrations through this layer. The insulation should have low absorption to minimize the loss of water from the fresh concrete during manufacturing the panel.

Several authors have attempted to optimize concrete sandwich elements. Their work focused mostly on standard thick walled concrete sandwich element where they attempted to reach full composite action and fulfil the requirements for thermal properties and material reduction. The literature review revealed that there is a lack of optimization studies in the design of HPCSPs. This fact is probably caused due to designers protect their optimization strategies as a result of competition among other producers. For thin plates, the work of Papanicolaou \& Triantafillou (2002) should be mentioned. They performed the procedure on minimum cost design of concrete sandwich panels made of HPC faces and PAC core for the case of in-plane and out-plane loading.

\section{Objective function}

The objective of HPCSP development is to establish the elements with the best structural and thermal performances and minimum cost. The present paper includes the material costs and ignores others such a transportation and assembly costs. In the case of HPCSPs the cost of mold is not taken into consideration as the cost is included in fix production plant investment costs. The cost 
function can be described as the sum of material cost functions that already include other costs, such as labour cost per unit volume. The total cost of HPCSP, $C$ per unit volume is shown beneath:

$$
C=\frac{t_{b}}{t} C_{H P C}+\frac{t_{f}}{t} C_{H P C}+\frac{t_{i n s}}{t} C_{i n s}+\rho_{s} \rho_{s h} C_{s h}
$$

where $t_{b}, t_{f}$ and $t_{\text {ins }}$ are the thicknesses of the back, front plate and insulation layer, respectively; $t$ is total thickness of the HPCSP. $C_{H P C}$ and $C_{i n s}$ stand for the cost per unit volume of the HPC layer and insulation layer, respectively, $C_{s h}$ is the cost of shear connectors/reinforcement per unit weight. $\rho_{s h}$ is shear connectors/reinforcement ratio along HPCSP height and length; $\rho_{s}$ stands for shear connectors/reinforcement density (density of steel/FRP).

\section{Constraints}

The producers and designers can set certain constraints to the design of the HPCSPs, e.g. maximum wall thickness, composition of the wall, choice of materials etc. Above all, material strength constrains should be applied to resist flexural, shear and face local buckling behaviour problem (ULS). The SLS constrain in sense of maximum horizontal/vertical deformations should be prescribed by national codes and standards or by structural requirements for openings. Furthermore, thermal resistance requirement has to be set as design constrain. The HPCSPs can be used as load carrying members as well as fill-in non-bearing members. Hence, the composite/noncomposite action of HPCSPs or particular degree of composite action has to be constrained prior to its optimization procedure. In the case of composite and partially composite load carrying HPCSPs the type of shear connectors/reinforcement ratio may be selected. Finally, the set of boundary conditions must be specified taking into account subgrade friction, temperature gradients over the thickness and connections between HPCSPs.

\section{Material cost function}

Conduct a study of the HPCSP's cost for the past two years, and establish change indicator for these costs. This requires cost data collection from current and previous projects and HPCSP materials suppliers. The collected data will be developed in a database to be used for cost references. Although the economic data of raw materials vary across regions and countries and are influenced by local costs of energy, labour and material resources, attention should not be focused on single cost values. The present cost study is used in order to draw useful conclusions on relative influences of design variables and variations on the HPCSPs cost and consequently to propose the optimum design solution.

\subsection{HPC plates}

Rougeron et al. (1994) and Ozbay et al. (2001) performed the studies on multi-objective mix proportioning optimization of HPC. Their studies may be implemented to find the optimum mix design for special performance characteristics. These characteristics should take into account structural requirements and production induced constraints, such as:

1. HPC mix must be designed to minimize autogenous shrinkage

2. Provide adequate strength to design load

3. High early age strength (time- related production cycles)

4. Durability (life time up to 100 years)

5. Improved crack control (avoiding damage risks during lifting, transport and assembly)

The total unit cost of HPC plates is equal to the sum of material and labour costs for all stages of production. The HPC cost is generally expressed as a non-linear function of its compressive strength for high-strength concretes (Papanicolaou \& Triantafillou 2002). 


\subsection{Insulation layer}

Bond between the insulation layer and HPC plates provides in the case of thin walled HPCSPs significant shear transfer, the shear stiffness depending on the insulation thickness. Hansen (2012) performed the optimization of the insulation thickness based on the energy performance requirement in European Union for 2020. The thickness was constrained to a maximum of $400 \mathrm{~mm}$. Optimizing without this constrain would result in unrealistic insulation thickness. The cost function for insulation layers can be described by linear function with an increasing cost/thickness gradient.

\subsection{Shear connecting system/Reinforcement}

The number and position of shear connectors and degree of reinforcement is dependent on required structural systems. The steel provides relatively cheap solution but it can negatively influence thermal efficiency of HPCSPs. An interesting option is using different kind of FRP materials which do not affect thermal efficiency. However, the cost may be relatively high in comparison with steel solution. The choice of material should be chosen prior to optimization procedure. Hence, the cost function of shear connecting system/reinforcement is equal to individual costs of used materials.

\section{Optimization procedure}

The design of full scale HPCSP usually requires a building block approach to testing and design. This approach involves increasing the testing complexity and size from small scale tests to full scale tests. The chemical and material tests in the first stages are generally well defined tests. As we move from the laminate level to sub-element component and sub-structure level the tests become more application dependent. Neither standard test methods nor databases exist for these large scale tests. Thus there is a need to reduce cost and increase the efficiency of structural design and structural failure prediction by a global local testing and analysis approach. The global local approach involves supporting the global tests and analyses used in traditional design approaches by critical local sub-element tests. These tests are intended to be in between a material and substructure test. They are cheaper to manufacture and test, and most importantly they are fully representative of structural configurations undergoing the same manufacturing processes and may even be cut from the real structure (Petras 1998). The testing procedure is used for verification and validation of numerical modelling performed in Abaqus FE software. The model has to take into account that improving some parameters can negatively influence other parameters. For instance significant thickness reduction of HPC plate may cause structural cracking. The numerical model with estimated geometrical proportions is a starting point for its design and optimization procedure. Multi-objective optimization is essential in the real design of HPCSP structures. The single objective simulated annealing was developed by Kirkpatrick et al. (1983). It is considered as the basis of the multi-objective optimization (Paya et al. 2008). The single objective optimization gives an optimum set of design variables with respect to single objective, while the same variables give an unacceptable design for other objectives. A reasonable design solution could be reached by using a combination of more than single objective by using multi-objective design optimization (Konak et al. 2006). The optimal set procedure is preferred in the multi-objective design optimization. In the movement from one solution to another solution, there is always an amount of loses in one objective to achieve some gain in the other objective.

The multi-objective optimization method gives a set of solutions and the best solution measured regarding to all objective functions. Engineers always like to get only one value from the set of solutions. Therefore, solving multi-objective optimization problems can be conducted by both searching and decision making (Awad et al. 2010).

Optimization process is closely related with environmental aspects, material reduction and cost reduction at the same time. Finding the optimum solution involves extended iterative calculations and, thus, need of powerful calculation tools. Optimization of all design parameters at the same time would lead to high number of iteration and to very complicated ways to find the convergence 
in the sense of the best economically and structurally efficient solution. Therefore, all the design constrains should be carefully set before its optimization process. The proper selection of constrains leads to the faster convergence solution and significant reduction of computation time. Figure 1 shows the proposed design optimization methodology of HPCSPs.

Optimization procedure for which the cost is minimum and all bearing capacity values exceeded the respective design values is needed solution. Its optimization procedure is consists of the four phases as follows:

a) The structural FE software Abaqus is used to perform structural optimization. It automates the design process for accuracy and speed purposes.

b) The quantity take-off computer program. This program measures the total quantities of HPCSPs on basis of measured units trough given set of dimensions and number of elements.

c) Computer aided cost estimation. The program uses the cost data functions from material cost database and the quantity take off procedure to calculate total cost of materials.

d) Cost optimization support system. The three programs of HPCSP design, quantity take-off and cost estimating, are integrated into a single system that would provide different costs for different HPCSP designs.

The minimum cost is achieved when design performance demands exceed the panel's capacity. It is clear that thicknesses of the HPC plates have to be the lowest possible. The functionality of the cost optimization system requires additional testing in an iterative mode to ensure reliability prior to final implementation. As a result of successful testing, parametric cost studies are conducted to determine the relationship between the HPCSP's dimensions and its cost.

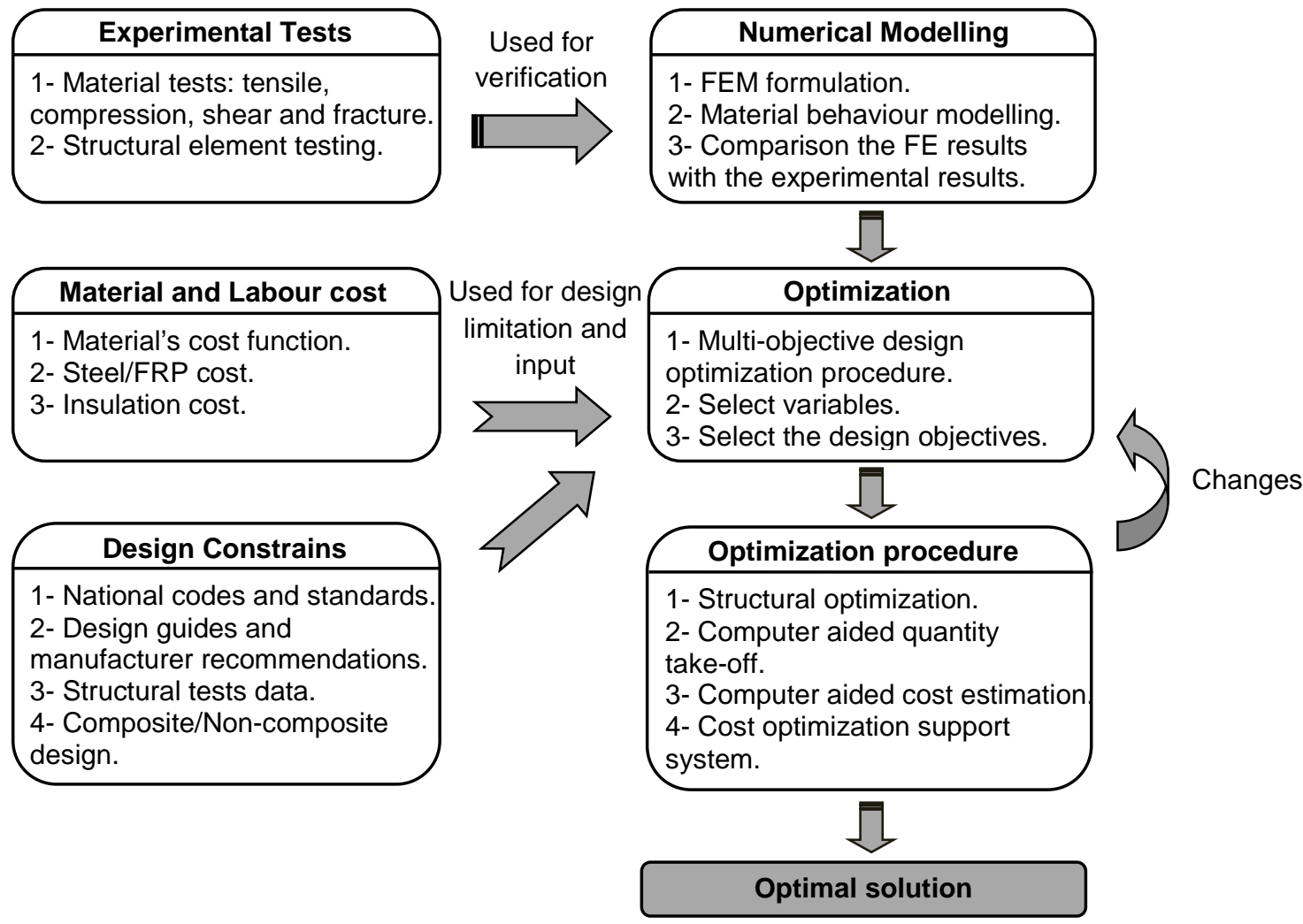

Fig. 1 Proposed design optimization methodology of HPCSPs. 


\section{Author's remarks}

Two of the HPC layers of the HPCSP are made in the fabrication process and their performance is a result of how that process is carried out. Therefore, an assessment of the HPCSP concept must be closely linked to a clearly specified manufacturing process including the quality system in operation to control manufacturing and any inspection and checks to confirm quality. Qualification of the HPCSP technology would have to address these novel aspects carefully in relation to the intended use of the technology over the service life and foreseeable accident scenarios. Above all, the producers and designers attempting to develop and optimize novel thin-walled HPCSPs should keep in mind the subsequent steps:

1) HPC mix must be designed to minimize autogenous shrinkage and provide adequate strength to design load. (risk of cracking in HPCSPs)

2) The bond between layers of thermal insulation, HPC plates and insulation must be carefully evaluated.

3) Number and position of the shear connectors must be specified to eliminate the structural cracking of HPC plates.

4) Shear connectors must provide adequate strength and stiffness for optimum composite/noncomposite action between the exterior HPC plates.

5) Shear connectors must be designed to eliminate thermal reduction of the panel through the thermal bridges.

6) No concrete penetrations through the insulation layer should exist.

7) The panels should be designed to withstand the applied loads.

\section{Conclusion}

The advantages of the HPCSPs make them attractive to be used in the building and construction industries recently. The challenge is to optimize the HPCSPs to achieve a high structural efficiency at minimum cost. Considering the limitations of the existing optimization methods, the authors proposed a design optimization procedure for HPCSPs. The multi-objective optimization method found to be the most suitable for HPCSPs allows considering different kind of variables and constraints. The method has several advantages but also some limitations. As costs of building materials vary across regions and countries and are influenced by local costs of energy, labour and material resources. The cost database requires regular updates and new inputs for different regions and countries. Nevertheless, further investigation is needed on the proposed methodology applied to different case studies to investigate its validity and limitations.

\section{References}

Awad, Z.K., Aravinthan, T., Zhuge, Y. \& Gonzalez, F. 2010. Multi-objective design optimization of an innovative fibre composite sandwich panel for civil engineering applications. Incorporating Sustainable Practice in Mechanics and Structures of Materials. Fragomeni, Venkatesan, Lam \& Setunge (eds.).CRC Press 2010, ISBN: 978-0-415-61657-7, pp. 801806.

Einea, A., Salmon, D.C., Tadros, M.K. \& Culp,T. 1994. A new structurally and thermally efficient precast sandwich panel system. PCI Journal, Vol. 39, Issue No. 4, pp. 90-101.

Frankl, B., Lucier, G., Rizkalla, S., Blaszak, G. \& Harmon, T. 2008. Structural Behavior of Insulated Prestressed Concrete Sandwich Panels Reinforced with FRP Grid; Fourth International Conference on FRP Composites in Civil Engineering (CICE2008), 22-24July 2008. Zurich, Switzerland. 
Hansen, S. 2012. Economical optimization of building elements for use in design of nearly zero energy buildings, Proceedings of the 5th IBPC, Kyoto, Japan, May 28-31, 2012, pp. 749755.

Kirkpatrick, S. \& Gelatt, C. 1983. Optimization by simulated annealing. Science 220(4598), pp. 671-680.

Konak, A., Coit, D.W. \& Smith, A.E. 2006. Multi-objective optimization using genetic algorithms: A tutorial. Reliability Engineering \& System Safety 91(9), pp. 992-1007.

Ozbay, E., Gesoglu, M. \& Guneyisi, E. 2011. Transport properties based multi-objective mix proportioning optimisation of high performance concretes, Materials and Structures, vol. 44, pp. 139-154.

Papanicolaou, C.G. \& Triantafillou, T.C. 2002. Minimum cost design of concrete sandwich panels made of HPC faces and PAC core: the case of in-plane loading, Journal: Structural Concrete, vol. 3, no. 4, pp. 167-181.

Paya, I., Yepes, V., Gonzalez-Vidosa, F. \& Hospitaler, A. 2008. Multiobjective optimization of concrete frames by simulated annealing. Computer-Aided Civil and Infrastructure Engineering 23(8):596-610.

Petras, A. 1998. Design of Sandwich Structures, Ph.D. thesis. Cambridge University Engineering Department.

Rizkalla, S.H., Hassan, T.K. \& Lucier, G. 2009. FRP Shear Transfer Mechanism for Precast, Prestressed Concrete Sandwich Load-Bearing Panels, Special Publication, Vol. 265, pp. 603625.

Rougeron, P. \& Aïtcin, P.-C. 1994. Optimization of the composition of a high-performance concrete. ASTM Journal of Cement, Concrete and Aggregates, Vol. 16, No. 2, pp. 115-124.

Salmon, D.C., Einea, A., Tadros, M.K. \& Culp T.D. 1997. Full scale testing of precast concrete sandwich panels, ACI Structural Journal, Vol. 94, No. 4, pp. 354-362.

Soriano, J. \& Rizkalla, S. 2013. Use of FRP Grid for the Composite Action of Concrete Sandwich Panels, Submitted to FRPRCS11 - 11th International Symposium on Fiber Reinforced Polymer for Reinforced Concrete Structures, June 26-28, 2013, Guimarães.

Wade, T.G., Porter, M.L., \& Jacobs, D.R. 1998. Glass-Fiber Composite Connectors for Insulated Concrete Sandwich Walls. Report, Engineering Research Institute, Iowa State University, Ames, IA. 